Tugas Individu

Mata Kuliah: Pendidikan Matematika II

Dosen Pengampuh: Jusmawati,S.Pd,.M.Pd

\title{
LUAS SELIMUT TABUNG
}

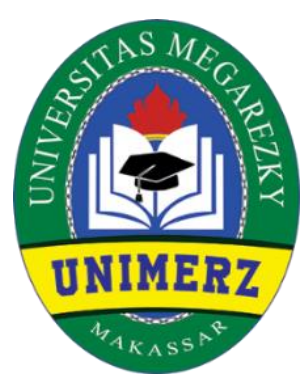

Disusun Oleh:

Asriani

18093188206035

S1 PENDIDIKAN GURU SEKOLAH DASAR (PGSD)

FAKULTAS KEGURUAN DAN ILMU PENDIDIKAN

UNIVERSITAS MEGAREZKY

T.A 2021/2022 


\section{KATA PENGANTAR}

Puji syukur kehadirat Tuhan Yang Maha Kuasa atas segala limpahan Rahmat dan Karunia-Nya sehingga saya dapat menyelesaikan penyusunan makalah ini. Semoga makalah ini dapat dipergunakan sebagai salah satu acuan, petunjuk, ataupun pedoman bagi pembaca dalam memahami bentuk bola dan kerucut.

Harapan saya semoga makalah ini membantu menambah pengetahuan dan pengalaman bagi para pembaca, sehingga saya dapat memperbaiki bentuk maupun isi makalah ini dan kedepannya dapat lebih baik lagi.

Makalah ini masih banyak kekurangan, oleh karena itu saya harapkan kepada para pembaca untuk memberikan masukan-masukan yang bersifat membangun untuk kesempurnaan makalah ini.

Takalar, 8 Februari 2021

ASRIANI 


\section{DAFTAR ISI}

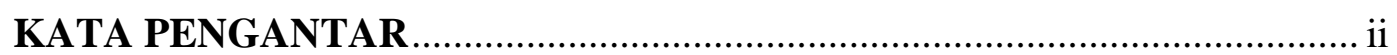

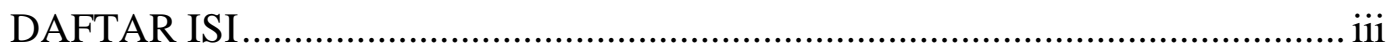

\section{BAB I PENDAHULUAN}

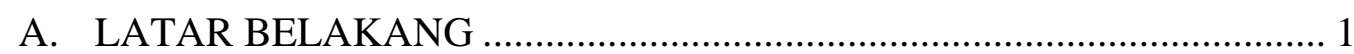

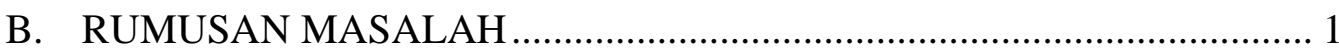

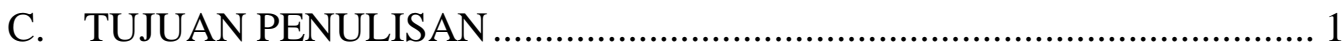

\section{BAB II PEMBAHASAN}
A. PENGERTIAN TABUNG 2

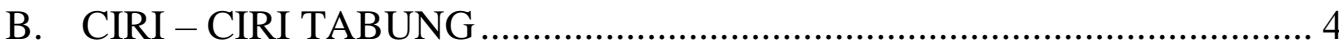

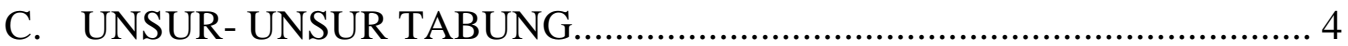

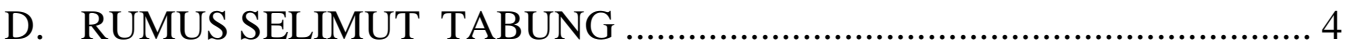

\section{BAB III PENUTUP}

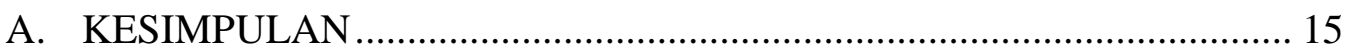

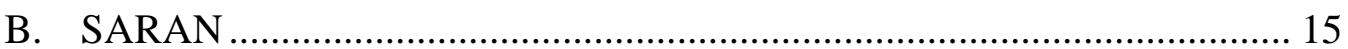

DAFTAR PUSTAKA 


\section{BAB I}

\section{PENDAHULUAN}

\section{A. LATAR BELAKANG}

Pengetahuan geometri dapat mengambangkan pemahaman anak terhadap dunia sekitarnya. Tidak hanya kemampuan tentang bangun datar, kemampuan tentang bangun ruangpun dapat dikenalkan kepada anak usia Sekolah Dasar bahkan pada anak usia Taman Kanak-kanak asalkan melalui pendekatan yang cocok dengan perkembangan tahap berfikir seorang anak.

Kemampuan bangun ruang akan membantu anak memahami, menggambarkan, atau mendekripsikan benda-benda di sekitar anak.

Anak akan lebih tertarik untuk mempelajari geometri jika mereka terlihat secara aktif dalam kegiatan-kegiatan individu atau kelompok berkenaan dengan geometri (bangunan-bangunan). Anak hendaknya diberi kesempatan untuk melakukan inventigasi secara individu atau kelompok dengan bantuan benda-benda kongkret di sekitar anak.

Di makalah yang kami buat ini, menjelaskan tentang sebuah bangun ruang Tabung. Lalu pada bab Pembahasan, kita akan lebih mengenal dan memahami tentang sebuah bangun ruang Tabung dan cara menentukan luas selimut tabung..

\section{B. RUMUSAN MASALAH}

1. Apa yang dimaksud dengan Tabung?

2. Apa saja ciri-ciri dan unsur-unsur tabung?

3. Bagaimana cara menentukan luas Selimut Tabung ?

\section{TUJUAN PENULISAN}

1. Mengetahui pengertian Tabung dan Selimut tabung

2. Mengetahui Ciri-ciri serta Unsur - unsur tabung

3. Mengetahui cara menentukan luas selimut tabung dengan menggunakan Rumus 


\section{BAB II}

\section{PEMBAHASAN}

\section{A. PENGERTIAN TABUNG}

Pengertian dari tabung ialah bangun ruang 3 dimensi yang dibentuk oleh 2 buah lingkaran identik yang sejajar dan sebuah persegi panjang yang mengelilingi kedua lingkaran tersebut. Tabung memiliki 3 sisi dan 2 rusuk.

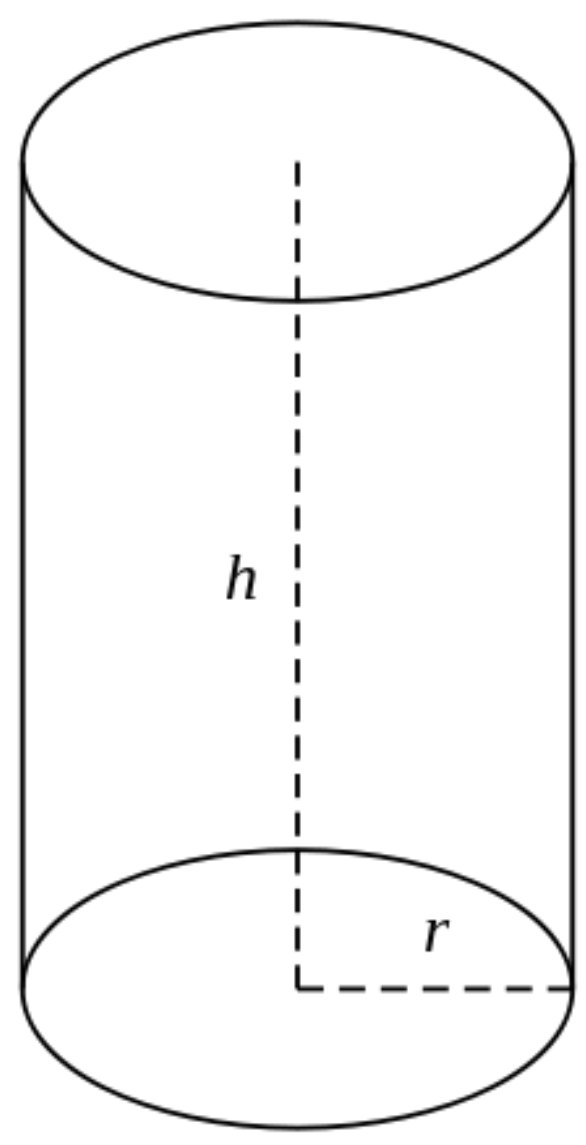

Kedua lingkaran disebut sebagai alas dan tutup tabung serta persegi panjang yang menyelimutinya disebut sebagai selimut tabung.

Selimut tabung ialah sisi lengkung yang berada di kiri dan kanan tabung yang membungkus atau menyelimuti tabung itu sendiri. 


\section{B. CIRI -CIRI SEBUAH TABUNG}

sebuah tabung memiliki sebuah ciri - ciri yaitu sebagai berikut :

1. Tabung mempunyai 2 rusuk

2. Alas dan tutup dari sebuah tabung berbentuk lingkaran

3. Tabung mempunyai 3 bidang sisi,sisi pertama adalah bidang alas, kedua bidang selimut, ketiga bidang tertutup

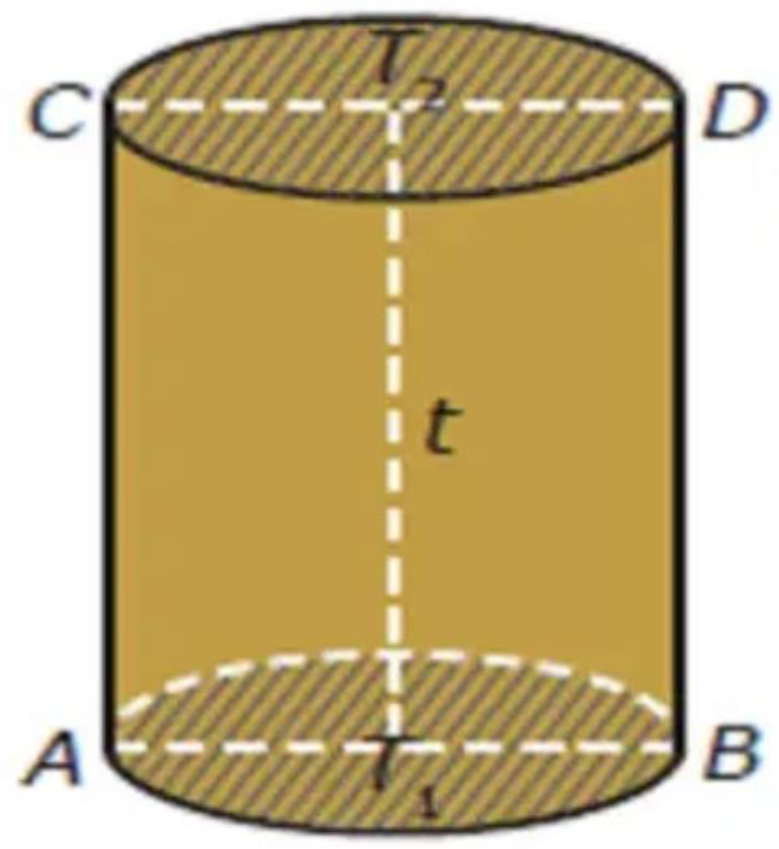

\section{Keterangan :}

- $\mathrm{r}=\mathrm{jari}-\mathrm{jari} /$ alas tabung

- $\mathrm{t}=$ tinggi tabung

Setelah kita melihat gambar tabung di atas kita bisa mendapat kan sebuah unsur unsur dari tabung maka, masuk ke tahap selanjut nya yaitu mengenai unsur - unsur yang di miliki oleh tabung : 


\section{UNSUR - UNSUR TABUNG}

Sebuah tabung memiliki Sebuah unsur-unsur sebagai berikut :

1. Sisi Tabung

Pengertian dari sisi ialah sisi yang berbentuk lingkaran dengan pusat nya berada di tengah, dan sisi atas yaitu sisi yang berbentuk lingkaran yang pusat nya sama berada di tengah.

2. Selimut Tabung

Pengertian dari selimut tabung ialah sisi lengkung yang berada di kiri dan kanan tabung.

3. Diameter Lingkaran Dari Sebuah Tabung

Pengertian dari diameter ialah ruas garis $\mathrm{AB}$, dan diameter lingkaran atas, yaitu ruas garis $\mathrm{CD}$.

4. Jari - Jari Lingkaran

Pengertian dari jari - jari ialah garis $\mathrm{T}_{1} \mathrm{~A}$ dan $\mathrm{T}_{1} \mathrm{~B}$, dan jari - jari bagian atas ialah garis $\mathrm{T}_{2} \mathrm{C}$ dan $\mathrm{T}_{2} \mathrm{D}$

5. Pusat Lingkaran Dari Sebuah Tabung

Salah satu dari unsur lingkaran yakni pusat lingkaran. Begitu juga dengan sebuah tabung, di mana titik $\mathrm{T}_{1}$ pada sisi alas dan $\mathrm{T}_{2}$ pada tutup tabung di namakan dengan pusat lingkaran. Dan pengertian dari pusat lingkaran ialah suatu titik tertentu yang mempunyai jarak yang sama terhadap semua titik pada lingkaran itu sendiri.

6. Tinggi Tabung 
Ruas garis yang menghubungkan titik $\mathrm{T}_{1}$ dan $\mathrm{T}_{2}$ itu lah yang di namakan dengan tinggi tabung, biasa nya di simbol kan dengan huruf $(t)$. Dan tinggi tabung di sebut juga dengan sumbu simetri putar tabung.

D. RUMUS LUAS SELIMUT TABUNG

Cara mencari luas selimut tabung sebenarnya dapat kita tentukan dengan menggunakan cara seperti di bawah ini :

- Luas Sebuah Selimut Tabung = keliling alas $\mathrm{x}$ tinggi tabung

- Luas Sebuah Selimut Tabung $=2$. $\pi$. $r$ x tinggi tabung

- Luas Sebuah Selimut Tabung $=2$. $\pi$. $\mathbf{x}$ t

Contoh Soal Luas Selimut Tabung

Soal :

1. Diketahui suatu tabung jari-jari alasnya $7 \mathrm{~cm}$ dan tingginya $20 \mathrm{~cm}$. Tentukan luas selimut tabung tersebut?

Jawab :

Diketahui :

$\mathrm{r}=7 \mathrm{~cm}$

$\mathrm{t}=20 \mathrm{~cm}$

Ditanyakan

Luas selimut tabung?

Penyelesaian:

- Luas selimut tabung $=2 \pi \mathrm{rt}$

$=2(22 / 7)$. 7.20

$=880 \mathrm{~cm}^{2}$ 


\section{Jadi, luas selimut tabung tersebut adalah $880 \mathrm{~cm}^{2}$}

\section{E. MODEL PEMBELAJARAN}

\section{Model pembelajaran Coperatif (STAD)}

Model pembelajaran kooperatif merupakan suatu kolaborasi antara objek atau subjek pembelajaran, fasilitas pembelajaran, lingkungan pembelajaran, serta prosedur pembelajaran yang saling mempengaruhi (Ardiyansyah et al., 2019) (Wijaya \& Arismunandar, 2018). Secara sederhana model pembelajaran koopertif dapat didefinisikan sebagai model pembelajaran yang dalam pelaksanaannya menggunakan kelompok sebagai wadah dalam pemecahan masalah suatu materi pembelajaran (Jamaludin \& Mokhtar, 2018) (Arie, 2017). Model pembelajaran ini dianggap paling utama dan berhasil dalam penerapannya. Metode yang digunakan didalamnya adalah dikusi dan kerja dalam kelompok yang diharapkan mampu meningkatkan 6 aspek keberhasilan pembelajaran yaitu meningat, memahami, menganalisa, menerapkan, dan mengevaluasi (Erina \& Kuswanto, 2015) (Marashi \& Tabatabayi, 2019). Ada beberapa tipe model pembelajaran kooperatif diantaranya : Model Jigsaw, Model Jigsaw II, Model Student Teams Achievement Division (STAD), Model Team Assisted Individualization (TAI), Teams Games Tournament (TGT), ModelCooperative Integrated Reading And Composition (CIRC), dan Model Number Head Together (NHT) (Wulandari \& Neolaka, 2013). Dalam hal ini akan dibahas lebih dalam Student Teams Achievment Division

(STAD). Student Team Achievment Division (STAD) digunakan untuk menyatukan berbagai karakteristik pemikiran peserta didik dalam satu kelompok (Marashi \& Tabatabayi, 2019) (Jambari \& Ratnasari, 2019).

Teknik yang pertamakali dicetuskan oleh slavin ini memiliki beberapa tahapan yaitu :

a. Persiapan pembelajaran, dapat berupa penyampaian tujuan pembelajaran oleh guru. 
b. Pembentukan kelompok sejumlah 4-6 peserta didik, dalam pembagiannya harus seheterogen mungkin dengan tujuan agar setiap peserta didik dapat membagi dan mendiskusikan segala kemampuan bawaan yang ada pada dirinya (Humairah, 2020) (Fausan \& Numbered, 2016).

c. Penyampaian materi secara umum oleh guru, dalam hal ini siswa akan di berikan sumber belajar yang akan meningkatkan kemampuan membaca dan menganalisisnya (Sutopo et al., 2020).

d. Membuat suatu kegiatan yang merangsang kerja individu dalam kelompok seperti diskusi, bertujuan agar peserta didik dapat bekolaborasi serta tidak lupa akan sikap menghormati serta menerima pendapat orang lain (Marashi \& Tabatabayi, 2019).

e. Memberi keluangan waktu untuk peserta didik memastikan bahwa semua anggota kelompok telah menguasai materi, pada saat ini peserta didik yang memiliki pemahaman lebih mengenai materi yang dibahas, akan secara aktif membantu peserta didik lain yang pemahamannya masih rendah terkait materi yang dibahas (Khairunnisa \& Aziz, 2019) (Jatmiko, 2017).

f. Membuat penilaian atau evaluasi, penilaian dilakukan secara individu yang kemudian diakumulasi sebagai nilai kelompok, penilaian juga dibuat dengan mengedepankan analisis tertulis agar peserta didik dapat melatih kemampuan bahasa tulisan serta mampu bertangung jawab atas kemampuannya untuk keberhasilan kelompok (Ilmi et al., 2012) (Burhannuddin et al., 2019) (Wati et al., 2018).

g. Memberi penghargaan terhadap kelompok yang berhasil memperoleh nilai tertinggi sebagai dorongan semangat untuk pembelajaran berikutnya (Rahmawati \& Mahmudi, 2014) (Lubis, 2012). Jika pembelajaran dengan model kooperatif tipe STAD ini berjalan dengan baik, maka tujuan pembelajaran akan tercapai serta terciptanya peserta didik yang terlatih dalam keterampilan mendengar, membaca, menganalisis dan menulis (Marashi \& Tabatabayi, 2019). 


\section{Model Matematika Realistik}

Pembelajaran Matematika Realistik (PMR) merupakan operasionalisasi dari suatu pendekatan pendidikan matematika yang telah dikembangkan di Belanda dengan nama Realistic Mathematics Education (RME) yang artinya pendidikan matematika realistik.

Model pembelajaran yang sesuai dengan materi luas selimut tabung adalah matematika realistik. Model pembelajaran matematika realistik merupakan teori belajar mengajar dalam pendidikan matematika. Model pembelajaran matematika realistik pada dasarnya adalah pemanfaatan realitas dan lingkungan yang dialami oleh siswa untuk melancarkan proses pembelajaran matematika, sehingga mencapai tujuan pendidikan matematika yang lebih baik daripada yang lalu.

Langkah-langkah dalam proses pembelajaran bangun ruang yaitu tabung dengan menggunakan model pembelajaran matematika realistik, sebagai berikut:

a. Memahami masalah kontekstual, yaitu guru memberikan masalah kontekstual dalam kehidupan sehari-hari dan meminta siswa untuk memahami masalah tersebut.

b. Menjelaskan masalah kontekstual, yaitu jika dalam memahami masalah siswa mengalami kesulitan, maka guru menjelaskan situasi dan kondisi dari soal dengan cara memberikan petunjuk petunjuk atau au berupa saran seperlunya, terbatas pada bagian-bagian tertentu dari permasalahan yang belum dipahami.

c. Menyelesaikan masalah kontekstual, yaitu siswa secara individual menyelesaikan masalah kontekstual dengan cara mereka sendiri. Cara pemecahan dan jawaban masalah berbeda lebih diutamakan. Dengan menggunakan lembar kerja, siswa mengerjakan soal. Guru memotivasi siswa untuk menyelesaikan masalah dengan cara mereka sendiri.

d. Membandingkan dan mendiskusikan jawaban, yaitu guru menyediakan waktu dan kesempatan kepada siswa untuk membandingkan dan 
mendiskusikan jawaban masalah secara berkelompok. Siswa dilatih untuk mengeluarkan ide-ide yang mereka miliki dalam kaitannya dengan interaksi siswa dalam proses belajar untuk mengoptimalkan pembelajaran.

e. Menyimpulkan, yaitu guru memberikan kesempatan kepada siswa untuk menarik kesimpulan tentang suatu konsep atau prosedur.

\section{F. METODE PEMBELAJARAN}

Metode pembelajaran yang akan kita gunakan dalam mempelajari materi Luas selimut tabung adalah metode tanya jawab. Metode tanya jawab adalah cara penyajian pelajaran dalam bentuk pertanyaan yang harus dijawab, terutama dari guru kepada siswa, tetapi dapat pula dari siswa kepada guru.

Langkah-langkah Dalam proses pembelajaran volume kerucut menggunakan metode tanya jawab adalah sebagai berikut:

1. Persiapan

a. menentukan topik

b. merumuskan tujuan pembelajaran khusus (TPK)

c. menyusun pertanyaan-pertanyaan secara tepat sesuai dengan TPK tertentu

d. mengidentifikasi pertanyaan-pertanyaan yang mungkin diajukan siswa

2. Pelaksanaan

a. Menjelaskan kepada siswa tujuan pembelajaran khusus (TPK)

b. Mengkomunikasikan penggunaan metode tanya jawab (siswa tidak han ya bertanya tetapi juga menjawab pertanyaan guru maupun siswa yang lain)

c. Guru memberikan permasalahan sebagai bahan apersepsi

d. Guru mengajukan pertanyaan keseluruh kelas

e. Guru harus memberikan waktu yang cukup untuk memikirkan jawabannya, sehingga dapat merumuskan secara sistematis 
f. Tanya jawab harus berlangsung dalam suasana tenang, dan bukan dalam suasana yang tegang dan penuh persaingan yang tak sehat di antara parasiswa

g. Pertanyaan dapat ditujukan pada seorang siswa atau seluruh kelas, guru perlu menggugah siswa yang pemalu atau pendiam, sedangkan siswa yang pandai dan berani menjawab perlu dikendalikan untuk memberi kesempatan pada yang lain

h. Guru mengusahakan agar setiap pertanyaan hanya berisi satu masalah saja

i. Pertanyaan ada beberapa macam, yaitu pertanyaan pikiran, pertanyaan mengungkapkan kembali pengetahuan yang dikuasai, dan pertanyaan yang meminta pendapat, perasaan, sikap, serta pertanyaan yang hanya mengungkapkan fakta-fakta saja.

\section{G. STRATEGI PEMBELAJARAN}

Strategi pembelajaran inkuiri merupakan rangkaian kegiatan pembelajaran yang menekankan pada proses berpikir kritis dan analitis untuk mencari dan menemukan sendiri jawaban dari suatu masalah yang dipertanyakan. Proses berpikir itu sendiri biasanya dilakukan melalui tanya jawab antara guru dan siswa.

Langkah-Langkah Pelaksanaan Strategi Pembelajaran Inkuiri

\section{Orientasi}

Langkah orientasi adalah langkah untuk menyesuaikan suasana atau iklim pembelajaran yang responsif. Pada langkah ini guru mengkondisikan agar siswa siap melaksanakan proses pembelajaran. Guru merangsang dan Mengajak siswa untuk berpikir memecahkan masalah. Langkah orientasi merupakan langkah yang sangat penting. Keberhasilan startegi ini sangat tergantung pada kemauan siswa untuk beraktivitas menggunakan kemampuannya dalam memecahkan masalah, tanpa kemauan dan kemampuan itu tak mungkin proses pembelajaran akan berjalan dengan lancar.

2. Merumuskan Masalah 
Merumuskan masalah merupakan langkah membawa siswa pada suatu masalah yang mengandung teka-teki. Persoalan yang disajikan adalah masalah yang menantang siswa untuk memecahkan teka-teki itu. Dikatakan teka-teki dalam rumusan masalah yang ingin dikaji disebabkan masalah itu tentu ada jawaban, dan siswa untuk mencari jawaban yang tepat. Proses mencari jawaban yang sangat penting dalam strategi inkuiri, oleh karena itu melalui melalui melalui siswa siswa akan memperoleh pengalaman yang sangat berharga sebagai upaya mengembangkan proses mental melalui proses berpikir.

\section{Merumuskan Hipotesis}

Hipotesis adalah jawaban sementara dari suatu permasalahan yang sedang dikaji. Sebagai jawaban sementara, hipotesis uji kebenarannya. Perkiraan sebagai hipotesis bukan perkiraan, tetapi harus memiliki landasan berpikir yang kokoh, sehingga hipotesis yang dimunculkan itu bersifat rasional dan logis. Kemampuan berpikir logis itu sendiri akan sangat dapat diandalkan oleh wawasan yang dimiliki serta keluasan pengala-manusia. Dengan demikian, setiap individu yang kurang berwawasan akan mengembangkan hipotesis yang rasional dan logis.

\section{Mengumpulkan Data}

Mengumpulkan data adalah aktivitas menjaring informasi yang dibutuhkan untuk menguji hipotesis yang diajukan. Dalam strategi pembelajaran inkuiri, kumpulkan data merupakan proses mental yang sangat penting da lam pengembangan intelektual. Proses data bukan hanya memerlukan motivasi yang kuat dalam belajar, tetapi juga membutuhkan ketekunan dan kemampuan menggunakan potensi berpikirnya. Karena itu, tugas dan peran guru dalam tahapan ini adalah mengajukan pertanyaanpertanyaan yang dapat mendorong siswa untuk berpikir mencari informasi yang dibutuhkan.

5. Menguji Hipotesis 
Menguji hipotesis adalah proses menentukan jawaban yang diterima sesuai dengan data atau informasi yang diperoleh berdasarkan data. Dalam hipotesis yang terpenting adalah mencari keyakinan tingkat jawaban atas jawaban yang diberikan. Dalam mengembangkan itu, hipotesis juga berarti kemampuan berpikir rasional. Artinya, jawaban yang diberikan bukan hanya berdasarkan argumentasi, tetapi harus didukung oleh data yang ditemukan dan dapat dipertanggungjawabkan.

\section{Merumuskan Kesimpulan}

Merumuskan kesimpulan adalah proses mendeskripsikan temuan yang diperoleh berdasarkan hasil pengujian hipotesis. Merumuskan suatu gong-nya dalam proses pembelajaran. Sering terjadi, karena data yang diperoleh, penyebab yang dirumuskan ti-dak fokus pada masalah yang dipecahkan. Karena itu, untuk akurat akurat akurat guru mampu menunjukkan pada siswa data mana yang relevan.

\section{H. PENDEKATAN PEMBELAJARAN}

Pendekatan yang kita gunakan pada materi ini yaitu problem solving. Problem solving atau penyelesaian masalah merupakan bagian dari proses berpikir. Pengertian pendekatan problem solving dapat dijelaskan sebagai sebuah metode perencanaan kerja yang meliputi penilaian, identifikasi masalah, perencanaan, implementasi, dan evaluasi. Langkah-Langkah Pembelajaran Problem Solving:

1. Klarifikasi masalah (Clarification of Problem)

Klarifikasi masalah meliputi pemberian penjelasan kepada setiap individu tentang masalah yang akan diajukan, agar setiap individu dapat memahami tentang penyelesaian seperti apa yang akan diharapkan.

\section{Pengungkapan pendapat (Brainstorming)}

Pada tahap ini diharapkan setiap individu dibebaskan untuk mengungkapkan pendapat tentang berbagai macam bagaimana cara menyelesaikan masalah. Suatu solusi masalah yang efektif, apabila kita berhasil menemukan sumber-sumber dan akar-akar dari masalah itu.

3. Evaluasi dan Pemilihan (Evaluation and Selection) 
Sedangkan pada tahapan ini, setiap individu dibagi dalam berbagai kelompok untuk mendiskusikan pendapat-pendapat atau cara-cara yang cocok untuk masalah tersebut,

\section{Implementasi (Implememtation)}

Pada tahapan ini setiap kelompok maupun individu harus mampu menentukan cara mana yang akan diambil untuk menyelesaikan masalah tersebut, kemudian menerapkannya sampai menemukan penyelesaian dari masalah tersebut. 


\section{Contoh Soal 1}

Hitunglah luas selimut dari sebuah tabung yang memiliki jari-jari alas $10 \mathrm{~cm}$ dan

tinggi $12 \mathrm{~cm}$.

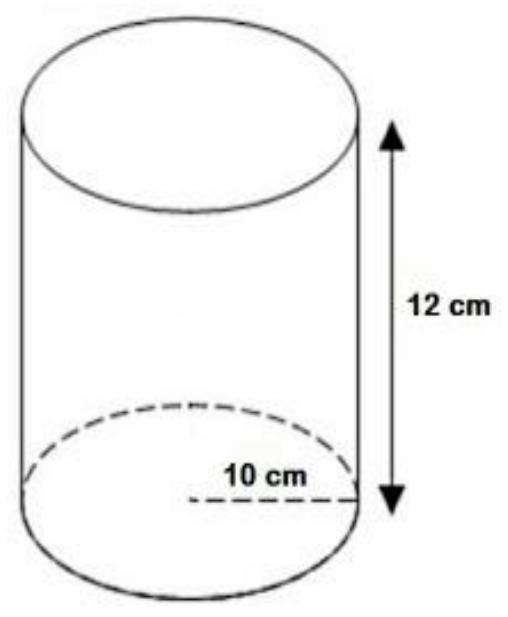

\section{Jawaban:}

Diketahui:

- $\mathrm{r}=10 \mathrm{~cm}$

- $\mathrm{t}=12 \mathrm{~cm}$

Ditanyakan:

- Luas Selimut Tabung

Penyelesaian:

- Luas Selimut Tabung $=2 \pi \mathrm{r} \times \mathrm{t}$

- $=2 \times 3,14 \times 10 \times 12$

- $\quad=753,6$ 


\section{BAB III}

\section{PENUTUP}

\section{A. KESIMPULAN}

Tabung ialah bangun ruang 3 dimensi yang dibentuk oleh 2 buah lingkaran identik yang sejajar dan sebuah persegi panjang yang mengelilingi kedua lingkaran tersebut. Tabung memiliki 3 sisi dan 2 rusuk.

Kedua lingkaran disebut sebagai alas dan tutup tabung serta persegi panjang yang menyelimutinya disebut sebagai selimut tabung.

Selimut tabung adalah sisi lengkung yang berada di kiri dan kanan tabung yang membungkus atau menyelimuti tabung itu sendiri.

\section{B. SARAN}

Demikian yang dapat Saya sampaikan mengenai materi yang menjadi pokok bahasan dalam makalah ini, tentunya masih banyak kekurangan, karena terbatasnya pengetahuan dan kurangnya rujukan atau referensi yang ada hubungannya dengan judul makalah ini. Kami berharap para pembaca memberikan kritik dan saran kepada kami supaya kami dapat memperbaiki makalah kami dan agar di kemudian hari kami tidak mengulangi kesalahan kami. Semoga makalah ini berguna bagi kami dan para pembaca juga. 


\section{DAFTAR PUSTAKA}

https://rumus.co.id/luas-selimut-tabung/

Heruman. 2007. model pembelajaran matematika. Bandung: PT. Remaja Rosdar Karya:

Mekar. 2010. CERMAT Cerdas Matematika. Ciamis: PT Mekar Mandiri.

Raharjo, Marsudi. 2009. Geometri Ruang. Yogyakarta: Departemen Pendidikan Nasional (BSE).

Sumanto, Y.D.; Heny Kusumawati; Nur Aksin. 2008. Gemar Matematika 5. Jakarta: Intan Pariwara 


\title{
RENCANA PELAKSANAAN PEMBELAJARAN ( R P P )
}

Nomor : 2.01

\author{
Nama Sekolah $\quad$ : Sekolah Dasar \\ Mata Pelajaran : Matematika \\ Kelas / Semester $\quad:$ VI / 1 (Ganjil) \\ Standar Kompetensi $\quad$ : 2. Memahami Ciri - ciri Tabung, serta menentukan luas Selimut tabung. \\ Kompetensi Dasar $\quad: 2.1$. Mengidentifikasi unsur - unsur tabung . \\ Indikator Pencapaian KD : $\quad$ Menuliskan unsur-unsur tabung, Ciri-ciri tabung Serta rumus \\ menentukan luas selimut tabung
}

\section{A. TUJUAN PEMBELAJARAN}

Setelah selesai pembelajaran, peserta didik diharap dapat :

Menuliskan unsur - unsur dari tabung, : sisi, diameter, tinggi, sisi, dan alas

Kemampuan prasyarat yang seharusnya sudah dikuasai siswa adalah :

1. membedakan bangun ruang sisi datar dan bangun ruang sisi lengkung,

2. menjelaskan sifat-sifat sifat-sifat lingkaran.

Karakter siswa yang diharapkan : Bersahabat/ Komunikatif, Cinta damai, Peduli Sosial, Tanggung jawab, Disiplin.

\section{B. MATERI PEMBELAJARAN}

Unsur-unsur tabung, kerucut dan bola.

\section{METODE PEMBELAJARAN}

1. Model Pembelajaran : Model pembelajaran Matematika Realistik/Coperatif tipe (STAD)

2. Metode Pembelajaran : Diskusi, Tanya Jawab dan Pemberian Tugas.

3. Strategi Pembelajaran : inkuiri

4. Pendekatan pembelajara : Problem solving/penyelesaian masalah

\section{LANGKAH-LANGKAH KEGIATAN PEMBELAJARAN}

1. Kegiatan Tatap Muka (TM). Alokasi Waktu : $2 \times 40$ menit (2 Jam Pelajaran) 


\begin{tabular}{|c|c|c|c|}
\hline KEGIATAN GURU & KEGIATAN SISWA & $\begin{array}{c}\text { WAKT } \\
\text { U }\end{array}$ & $\begin{array}{l}\text { KETERANGA } \\
\qquad \mathbf{N}\end{array}$ \\
\hline \multicolumn{2}{|c|}{$\begin{array}{l}\text { Fase } 1 \\
\text { Menyampaikan tujuan dan memotivasi siswa }\end{array}$} & \pm 5 & $\begin{array}{l}\text { PENDAHULUA } \\
\mathbf{N}\end{array}$ \\
\hline $\begin{array}{l}\text { Mengawali pembelajaran dengan } \\
\text { cara : } \\
\text { 1. Memotivasi siswa dengan } \\
\text { cara bertanya kepada siswa } \\
\text { mengenai benda-benda yang } \\
\text { ada disekitar mereka yang } \\
\text { berbentuk tabung, kerucut dan } \\
\text { bola. } \\
\text { 2. Mengingatkan kembali } \\
\text { tentang materi prasyarat } \\
\text { 3. Menyampaikan tujuan } \\
\text { pembelajaran. }\end{array}$ & $\begin{array}{l}\text { - Memperhatikan penjelasan } \\
\text { guru. }\end{array}$ & & \\
\hline \multicolumn{2}{|c|}{$\begin{array}{c}\text { Fase } 2 \\
\text { Menyajikan informasi }\end{array}$} & $\pm \mathbf{1 0}$ & $\begin{array}{l}\text { KEGIATAN } \\
\text { INTI }\end{array}$ \\
\hline $\begin{array}{l}\text { Memberikan informasi awal } \\
\text { tentang unsur-unsur tabung, } \\
\text { kerucut, dan bola }\end{array}$ & $\begin{array}{l}\text { Memperhatikan penjelasan } \\
\text { guru dan memberi } \\
\text { tanggapan bila guru } \\
\text { memberikan pertanyaan. } \\
\text { - } \text { Membaca dan menyimak } \\
\text { buku paket halaman } 40 .\end{array}$ & & Presentasi Kelas \\
\hline \multicolumn{2}{|c|}{$\begin{array}{c}\text { Fase } 3 \\
\text { Mengorganisasikan siswa ke dalam kelompok-kelompok belajar }\end{array}$} & \pm 5 & $\begin{array}{c}\text { BELAJAR } \\
\text { KELOMPOK }\end{array}$ \\
\hline $\begin{array}{l}\text { Mengelompokkan siswa ke } \\
\text { dalam kelompok-kelompok kecil } \\
\text { yang terdiri dari 4-5 orang } \\
\text { dengan memperhatikan tingkat } \\
\text { prestasi, jenis kelamin, sehingga } \\
\text { kelompok yang terbentuk }\end{array}$ & $\begin{array}{l}\text { Mengatur tempat duduk } \\
\text { dan mengelompokkan diri } \\
\text { sesuai dengan } \\
\text { kelompoknya. }\end{array}$ & & $\begin{array}{l}\text { Guru } \\
\text { membagikan } \\
\text { LKS } 2.01 \\
\text { kepada masing- } \\
\text { masing } \\
\text { kelompok }\end{array}$ \\
\hline
\end{tabular}




\begin{tabular}{|c|c|c|c|}
\hline KEGIATAN GURU & KEGIATAN SISWA & $\begin{array}{c}\text { WAKT } \\
\text { U }\end{array}$ & $\begin{array}{c}\text { KETERANGA } \\
\mathbf{N}\end{array}$ \\
\hline $\begin{array}{l}\text { merupakan kelompok yang } \\
\text { heterogen. } \\
\text { - Membagikan LKS } 2.01 \text { kepada } \\
\text { siswa. }\end{array}$ & - Menerima LKS 2.01. & & \\
\hline Membimbing kelompok & $\begin{array}{l}4 \\
\text { bekerja dan belajar }\end{array}$ & \pm 40 & \\
\hline $\begin{array}{l}\text { Memberikan kesempatan kepada } \\
\text { siswa untuk membaca LKS } 2.01 \text {, } \\
\text { dan bertanya jika ada hal-hal } \\
\text { yang belum dipahami mengenai } \\
\text { permasalahan dalam LKS } 2.01 . \\
\text { - Meminta siswa untuk } \\
\text { mengerjakan LKS } 2.01 \text { secara } \\
\text { berkelompok dengan anggota } \\
\text { kelompoknya masing-masing. } \\
\text { Mengawasi kerja kelom-pok } \\
\text { dengan mendatangi kelompok } \\
\text { dan memberi bantuan bila ada } \\
\text { kesulitan dengan memberikan } \\
\text { pertanyaan yang sifatnya } \\
\text { pancingan, bukan memberi } \\
\text { jawaban. } \\
\text { Meminta beberapa siswa } \\
\text { mewakili kelompoknya untuk ke } \\
\text { depan kelas mempresentasekan } \\
\text { jawaban berdasarkan hasil } \\
\text { diskusi kelompok, sedangkan } \\
\text { kelompok lain memberikan } \\
\text { tanggapan. }\end{array}$ & 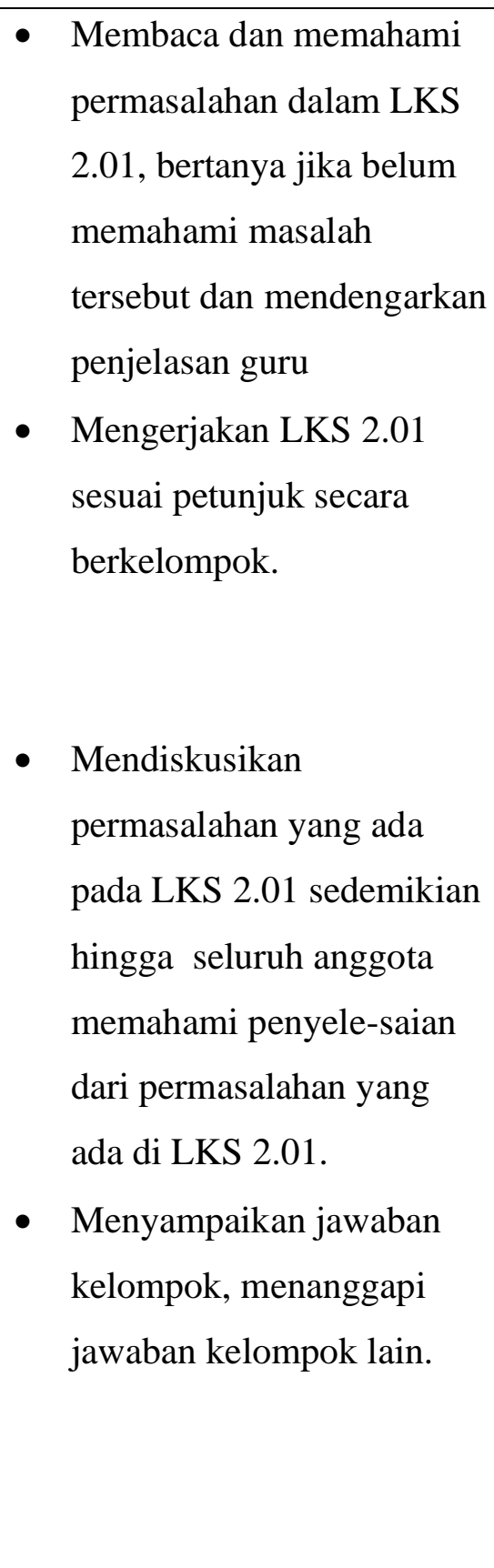 & & \\
\hline
\end{tabular}




\begin{tabular}{|c|c|c|c|}
\hline KEGIATAN GURU & KEGIATAN SISWA & $\begin{array}{c}\text { WAKT } \\
\text { U }\end{array}$ & $\begin{array}{c}\text { KETERANGA } \\
\mathbf{N}\end{array}$ \\
\hline \multicolumn{2}{|c|}{$\begin{array}{c}\text { Fase } 5 \\
\text { Evaluasi }\end{array}$} & \pm 15 & KUIS \\
\hline $\begin{array}{l}\text { - Meminta siswa untuk kembali ke } \\
\text { tempat duduk semula. } \\
\text { - Membagikan kuis individu. } \\
\text { berakhir. } \\
\text { Meminta siswa untuk } \\
\text { menukarkan pekerjaannya } \\
\text { dengan pekerjaan teman } \\
\text { sebangkunya kemudian } \\
\text { memeriksa dengan mengacu } \\
\text { pada kunci jawaban yang telah } \\
\text { disiapkan. } \\
\text { Meminta masing-masing ketua } \\
\text { kelompok mengumpulkan skor } \\
\text { kuis teman kelompoknya } \\
\text { masing-masing. } \\
\text { Merekap hasil kuis dan } \\
\text { menghitung skor kemajuan } \\
\text { setiap siswa dan menetapkan } \\
\text { predikat penghargaan kelompok }\end{array}$ & $\begin{array}{l}\text { - Masing-masing kembali ke } \\
\text { tempat duduk semula. } \\
\text { - Menerima kuis dan } \\
\text { - Wengerjakan kuis individu } \\
\text { berakhir. } \\
\text { - Menukarkan pekerjaan } \\
\text { dengan pekerjaan teman } \\
\text { sebangku kemudian } \\
\text { memeriksa dengan } \\
\text { mengacu pada kunci } \\
\text { jawaban yang telah } \\
\text { disiapkan. } \\
\text { Setiap anggota kelompok } \\
\text { menyerahkan skor kuisnya } \\
\text { masing-masing kepada } \\
\text { ketua kelompoknya. } \\
\text { Menunggu pengumuman } \\
\text { peng-hargaan } \\
\text { kelompoknya masing- } \\
\text { masing. }\end{array}$ & & $\begin{array}{l}\text { SKOR } \\
\text { KEMAJUAN }\end{array}$ \\
\hline $\begin{array}{r}\text { Fase 6 } \\
\text { Memberikan pe }\end{array}$ & nghargaan & \pm 5 & $\begin{array}{l}\text { PENGHARGAA } \\
\text { N KELOMPOK }\end{array}$ \\
\hline $\begin{array}{l}\text { - Memberikan penghargaan kepada } \\
\text { masing-masing kelompok } \\
\text { berdasarkan hasil kuis dan poin } \\
\text { kemajuan. } \\
\text { - Mengarahkan siswa membuat } \\
\text { kesimpulan. }\end{array}$ & 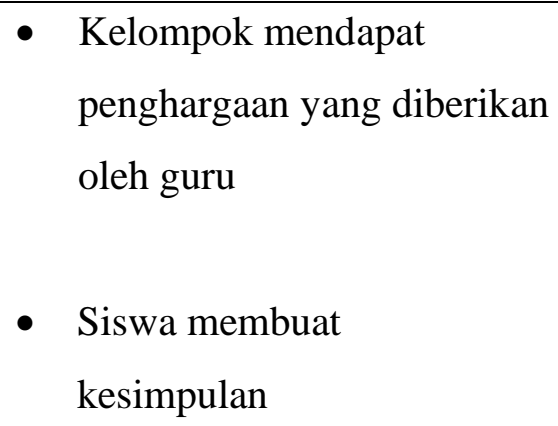 & & PENUTUP \\
\hline
\end{tabular}




\begin{tabular}{|c|c|c|c|}
\hline KEGIATAN GURU & KEGIATAN SISWA & \begin{tabular}{|c} 
WAKT \\
U
\end{tabular} & $\begin{array}{c}\text { KETERANGA } \\
\mathbf{N}\end{array}$ \\
\hline 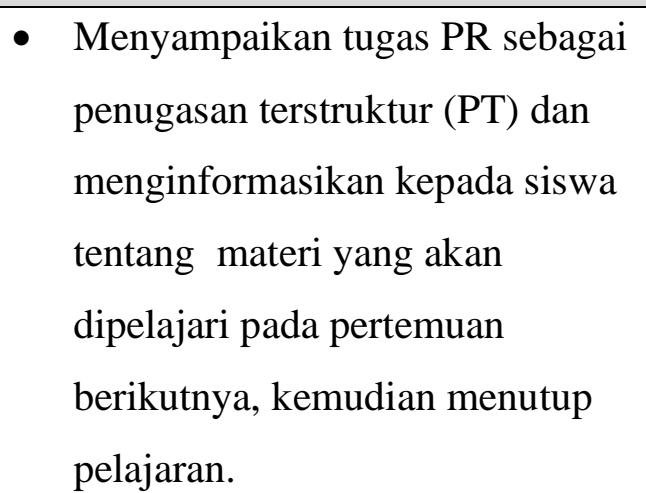 & $\begin{array}{l}\text { - Mencatat tugas RP yang } \\
\text { akan dikerjakan di rumah. }\end{array}$ & & \\
\hline
\end{tabular}

2. Kegiatan Penugasan Terstruktur (PT). Alokasi Waktu : 40 menit

Melakukan identifikasi ulang nama unsur-unsur dari gambar tabung, kerucut, dan bola yang diberikan.

E. SUMBER BELAJAR:

- Buku paket BSE Contextual Teaching and Learning Matematika SMP Kelas IX, R. Sulaiman dkk.

- Model bangun tabung, kerucut, dan bola

- LKS 2.01

- Bahan kuis

F. PENILAIAN HASIL BELAJAR :

Jenis Tes $\quad$ : Tertulis

Bentuk instrumen : Jawaban singkat

Instumen : Kuis (terlampir)

Mengetahui,

Makassar,8 Februari 2021

Dosen Pembimbing

Guru Mata Pelajaran,

Jusmawati S.Pd.,M.Pd

NIP : -
Asriani.

NIM : 18093188206035 
